\title{
Aetiology of Meningitis in Paediatric Age Group at a Tertiary Care Centre in Hyderabad, India - A Cross Sectional Study
}

\section{Dr Shaik Sumayyah Banuํㅜ, Dr D SudhaMadhuri ${ }^{1 *}$ and Dr P Shashikala Reddy $^{2}$}

${ }^{1}$ Department of Clinical Microbiology, Niloufer Hospital for Women and Children, Hyderabad, India

${ }^{2}$ Department of Clinical Microbiology, Osmania Medical College, Hyderabad, India
Received: October 20, 2021

Published: November 12, 2021

(C) All rights are reserved by

Dr D SudhaMadhuri., et al.

*Corresponding Author: Dr D SudhaMadhuri, Department of Clinical Microbiology,

Niloufer Hospital for Women and Children, Osmania Medical College, Hyderabad, India

\begin{abstract}
Background: Meningitis continues to be a serious public health problem that requires early prompt diagnosis and treatment. There is a need for a periodic review of meningitis since the pathogens responsible for the infection vary with time, geography, and patient age. The aim of this study is to identify the aetiological agents in suspected paediatric meningitis cases attending tertiary care hospital.

Methods: This cross- sectional study was conducted for a period of one year (August 2018-2019) in the Department of Clinical Microbiology, Niloufer hospital for Women and Children, Hyderabad after obtaining clearance from institutional ethical committee. Out of 135 suspected meningitis cases, 79 were enrolled into the study based on inclusion criteria. CSF samples collected by Lumbar Puncture and were processed immediately by standard conventional techniques for identification of bacteria, fungi, parasites and ELISA for IgM antibodies against viral antigens of HSV 2, VZV, EV 71. The demographic data and associated laboratory findings were analysed in detail.

Results: Out of 79 samples, 32 (40.5\%) were confirmed as meningitis of bacteria and viral aetiology. No fungal and parasitic agents were identified. Prevalence of viral meningitis (32.9\%) was found to be more than bacterial meningitis (7.5\%). The most common viral agent was HSV2 (61.5\%) followed by VZV (38.4\%). Among bacterial pathogens, Gram negative organisms (66.6\%) were more than Gram positive organisms (33.3\%). Infants and neonates were most commonly affected. Out of 15 districts covered, maximum number of viral meningitis cases were reported in and around Hyderabad during spring and winter seasons.

Conclusion: To conclude, Viruses played a predominant role as compared to bacteria in paediatric meningitis and this was dictated by factors like endemicity, geography and season. There is a need for more studies to identify the emerging aetiologies of paediatric meningitis.
\end{abstract}

Keywords: Paediatrics; Viral Meningitis; HSV2; VZV; Bacterial Meningitis

\section{Introduction}

Meningitis is defined as inflammation of the meninges, a thin membranous coverings of the brain and the spinal cord [1]. Meningitis is a serious public health problem that requires early diagnosis, treatment, and preventive measures [2]. It is a notifiable disease with significant morbidity and mortality. Neonates are more prone to meningitis due to immature immune system and increased permeability of blood-brain barrier (BBB) [3]. The incidence of meningitis shows regional and seasonal variation. Latest estimated global burden is 2.82 million (2016). The incidence of meningitis in neonates and children under $5 y$ rs age group is $56 \%$ with a mortality of $46 \%[3,4]$. In the Indian scenario, bacterial ae- 
tiology accounts for $55.3 \%$ of cases in below 1yr age group [4,5]. There is insufficient published data regarding viral meningitis [5,6]. However, few record based Indian studies reported $43.3 \%$ viral meningitis cases in paediatric age group [6,7]. S. pneumoni$a e, N$. meningitidis, $H$. influenzae, $L$. monocytogenes, and $S$. aureus are important bacterial pathogens of acute bacterial meningitis in the west but the relative incidence of these is less in South East Asia where $P$. aeruginosa, E. coli, and K. pneumoniae are important pathogens [8]. The most common viral meningitis pathogens are non-polio enteroviruses, herpes simplex viruses, mumps measles and influenza viruses. Among fungal pathogens, Cryptococcus neoformans is most common in children with immunodeficiencies. Parasitic meningitis is due to causes like $N$. fowleri, A. cantonensis, B. procyonis, G. spinigerum (CDC 2019) [9,10]. The main objectives of the present study is identification of aetiological agents in suspected paediatric meningitis patients and analysis of demographic, clinical and laboratory data.

\section{Materials and Methods}

The Present study was conducted for a period of 1 year (August 2018-2019) at the Department of Clinical Microbiology, Niloufer hospital for Women and Children, Osmania Medical College, Hyderabad. Clearance from institutional ethical committee [Osmania medical college-ECR/300/Inst/AP/2013/RR-16] was obtained. Out of 135 suspected meningitis cases, 79 were enrolled into the study based on inclusion criteria. Inclusion criteria was neonates, infants and children upto 12 yrs attending to the hospital with clinical history suggestive of meningitis. Exclusion criteria was all cases with tubercular meningitis, iatrogenic meningitis, non-infectious meningitis and age above 12yrs. Informed consent was obtained from parents/guardians after explaining in detail the objectives of the study. The details of all patients including demographic data, clinical history, clinical examination notes, prior investigations done and treatment history was documented and analysed. CSF samples from all cases in study group were collected in sterile containers by Lumbar Puncture using standard techniques under aseptic conditions by clinicians. The CSF sample was divided into 2 parts. One part was sent for culture and microscopy to identify bacterial and fungal aetiologies. Second part was preserved at $-20^{\circ} \mathrm{C}$ and sent for serological diagnosis of viral aetiology by IgM ELISA antibody test for HSV 2, VZV, EV-71 antigens. Samples were processed without any delay. The samples were centrifuged at $1000 \mathrm{x}$ $\mathrm{g}$ for 10-15 minutes. The sediment of centrifuged sample was subjected for culture and microscopic examination for bacterial and fungal processing by standard microbiological conventional meth- ods. Culture isolates were identified based on biochemical reactions and further subjected to Antimicrobial susceptibility testing as per CLSI guidelines. Fungal cultures were observed for growth at $48 \mathrm{hrs}, 72 \mathrm{hrs}$ and weekly upto $4 \mathrm{wks}$. For detection of parasites, wet mounts were examined microscopically for trophozoites of $N$. fowlerii and larvae of helminthic parasites like A. cantonensis, $B$. procyonis, G. spinigerum.

Serological test (ELISA) for viral agents: The $2^{\text {nd }}$ sample which was preserved at $-20^{\circ} \mathrm{C}$ was subjected to Quantitative IgM ELISA as per manufacturer's literature protocol for HSV 2, VZV, EV71 viruses using HSV IgM (Cat no: E13652595), VZV IgM (Cat no: E13651838), EV71 IgM (Cat no: E13652113) ELISA Kits of Sincere Biotech. Ltd company, Beijing, China. Purified Human HSV 2/VZV/EV 71 antigen coated microtiter plate wells were used to detect specific IgM antibodies in CSF samples. The ELISA results were analysed within the detection range of $61.35 \mathrm{pg} / \mathrm{ml}-5000 \mathrm{pg} / \mathrm{ml}$ by considering Standard 4 as cut off value.

\section{Results, Discussion and Conclusion}

Out of $79 \mathrm{CSF}$ samples processed, 32 (40.5\%) were confirmed as meningitis by bacteria and viruses. No fungal and parasitic aetiology were found. The prevalence of viral meningitis ( $n=26 ; 32.9 \%$ ) was found more than bacterial meningitis $(n=6 ; 7.5 \%)$. Among the tested viral aetiological agents, the most common was HSV2 (61.5\%) followed by VZV (38.4\%) (Table 1). 50\% neonates showed bacterial aetiologies whereas $38.4 \%$ infants showed viral aetiologies with decreasing trend as the age advances. The most common clinical presentation of study group was convulsions followed by fever. Non-specific symptoms like rash, vesicles, loose stools, vomitings, upper respiratory tract symptoms were more associated with viral meningitis. Radio-imaging studies showed Normal CT/MRI Brain scans in $69.6 \%(n=55)$ indicating meningitis in the study group. Geographical distribution among 15 districts covered in

\begin{tabular}{|l|c|c|}
\hline Type & Organism & Positive cases (\%) \\
\hline \multirow{3}{*}{ Bacteria } & S. aureus & $2(33.3 \%)$ \\
\cline { 2 - 3 } & E.coli & $2(33.3 \%)$ \\
\cline { 2 - 3 } & K. pneumoniae & $2(33.3 \%)$ \\
\hline \multirow{2}{*}{ Viruses } & HSV2 & $16(61.5 \%)$ \\
\cline { 2 - 3 }$(n=26)$ & VZV & $10(38.4 \%)$ \\
\cline { 2 - 3 } & EV71 & Nil \\
\hline Fungi & Nil & Nil \\
\hline Parasites & Nil & Nil \\
\hline
\end{tabular}

Table 1: Aetiological agents identified in meningitis cases. 
this study showed maximum viral meningitis cases in and around Hyderabad district and bacterial meningitis cases were equally distributed in Rangareddy, Kamareddy, Mahbubnagar, Nalgonda, Sangareddy, Vikarabad districts. Seasonal distribution showed gradual increase in no. of viral meningitis cases in January, February then peak was observed in March followed by fall in number of cases and nil cases in May, June, July and again gradual increase in number of cases in August, September with shorter peak in October followed by fall in November and nil cases in December (Table 2).

\begin{tabular}{|c|c|c|c|c|}
\hline \multicolumn{3}{|c|}{ Characteristic } & $B M(n=6)$ & VM (n = 26) \\
\hline \multirow[t]{2}{*}{ Gender } & \multicolumn{2}{|l|}{ Males } & $50 \%(\mathrm{n}=3)$ & $46.2 \%(n=12)$ \\
\hline & \multicolumn{2}{|l|}{ Females } & $50 \%(n=3)$ & $53.8 \%(\mathrm{n}=14)$ \\
\hline \multirow[t]{3}{*}{ Age } & \multicolumn{2}{|c|}{ Neonates (Day 0 to Day 30) } & $50 \%(\mathrm{n}=3)$ & $34.6 \%(n=9)$ \\
\hline & \multicolumn{2}{|c|}{ Infants (Day 31- 12 months) } & $33.3 \%(n=2)$ & $38.4 \%(n=10)$ \\
\hline & \multicolumn{2}{|c|}{ Children (1 year-12 years) } & $16.7 \%(n=1)$ & $27 \%(n=7)$ \\
\hline Geography & \multicolumn{2}{|l|}{ Hyderabad District } & Nil & $34.6 \%(n=9)$ \\
\hline Season & & & Spring, Winter & Winter \\
\hline \multirow[t]{2}{*}{ Clinical Features } & \multicolumn{2}{|l|}{ Specific } & $66.7 \%(n=4)$ & $73 \%(n=19)$ \\
\hline & \multicolumn{2}{|l|}{ Non-specific } & & $57.6 \%(n=15)$ \\
\hline \multirow[t]{2}{*}{ Duration of illness } & \multicolumn{2}{|l|}{ Acute $(<72$ hrs $)$} & $50 \%(n=3)$ & $61.5 \%(n=16)$ \\
\hline & \multicolumn{2}{|l|}{ Sub acute $(>72 \mathrm{hrs})$} & $50 \%(n=3)$ & $38.4 \%(n=10)$ \\
\hline \multirow[t]{10}{*}{ Laboratory analysis } & \multicolumn{2}{|c|}{ Serum CRP (>10 mg/l) } & $100 \%(n=6)$ & $26.9 \%(n=7)$ \\
\hline & \multirow{3}{*}{$\begin{array}{c}\text { Blood WBC } \\
\text { (Newborns:9,000-30,000 } \\
\text { <2yrs: } 6,200-17,000 \\
>2 \text { yrs:5,000-10,000) }\end{array}$} & Raised & $66.7 \%(n=4)$ & - \\
\hline & & Low & & $23.1 \%(n=6)$ \\
\hline & & Normal & $33.3 \%(n=2)$ & $76.9 \%(n=20)$ \\
\hline & \multirow{2}{*}{$\begin{array}{l}\text { CSF Glucose } \\
(60-80 \mathrm{mg} / \mathrm{dl})\end{array}$} & Low & $100 \%(n=6)$ & $26.9 \%(n=7)$ \\
\hline & & Normal & & $73.1 \%(n=19)$ \\
\hline & \multirow{2}{*}{$\begin{array}{l}\text { CSF Proteins } \\
\text { (Newborn: 40-120; } \\
\text { <1 month: } 20-80 ; \\
>1 \text { month:15-40mg/dl) }\end{array}$} & Raised & $33.3 \%(n=2)$ & $80.8 \%(n=21)$ \\
\hline & & Normal & $66.7 \%(n=4)$ & $19.2 \%(n=5)$ \\
\hline & \multirow{2}{*}{$\begin{array}{c}\text { CSF cell count } \\
\text { (Pleocytosis: } \\
\text { Neonates: }>10 \text { white cells } / \mathrm{mm}^{3} \\
\text { Others: }>5 \text { white cells } / \mathrm{mm}^{3} \text { ) }\end{array}$} & $\begin{array}{l}\text { Neutrophils } \\
\text { High }\end{array}$ & $100 \%(n=6)$ & - \\
\hline & & $\begin{array}{c}\text { Lymphocytes } \\
\text { High }\end{array}$ & - & $100 \%(n=26)$ \\
\hline \multirow{2}{*}{$\begin{array}{l}\text { Radio-imaging } \\
\text { CT/MRI brain scans }\end{array}$} & \multicolumn{2}{|l|}{ Normal } & $83.3 \%(n=5)$ & $73.1 \%(n=19)$ \\
\hline & \multicolumn{2}{|c|}{\begin{tabular}{|c|} 
Abnormal (Prominent ventricles, Hypodensity of basal \\
ganglia/cerebellar region/parietal lobes/Rt. cerebral \\
cortex/Superior sagittal sinus/Thickened cortex, Rt. \\
thalamus infarct/Brainstem ischemia)
\end{tabular}} & $16.7 \%(\mathrm{n}=1)$ & $26.9 \%(n=7)$ \\
\hline \multirow[t]{3}{*}{ Outcome } & \multicolumn{2}{|l|}{ Recovered } & $83.3 \%(n=5)$ & $88.5 \%(n=23)$ \\
\hline & \multicolumn{2}{|l|}{ Neurological sequele } & - & $7.7 \%(n=2)$ \\
\hline & \multicolumn{2}{|l|}{ Deaths } & $16.7 \%(n=1)$ & $3.8 \%(n=1)$ \\
\hline
\end{tabular}

Table 2: Demographic, Clinical, Laboratory data of confirmed cases.

BM: Bacterial meningitis; VM: Viral meningitis. 
In the present study, Hyderabad showed high preponderance for paediatric meningitis during spring and winter seasons which is a point of concern. The suspected meningitis cases in study group were mainly of neonates and infants accounting for $77.2 \%$. It was observed that paediatric age group was highly affected with viral meningitis (32.9\%) which is in consistent with Borade., et al. study (43.29\%) [7]. In the present study, HSV2 accounted for $61.5 \%$ and VZV for 38.4\% whereas Pormohammad., et al. [11] study reported 9.8\% VZV and 1.4\% HSV 1/2. Even though Enteroviruses causes 70$95 \%$ of aseptic meningitis [10], but the present study showed nil cases of IgM antibody against EV71. According to another study in Turkey including children and adults, herpesviruses, were observed more than enteroviruses [12]. The reason for higher herpesviruses in our study can be due to history of maternal antenatal TORCH infections and contagious transmission of infections from infected siblings/family members. In the present study, we have adopted quantitative IgM ELISA test for detection of viral aetiologies. This is in consistent with explanation by Stiernstedt., et al. [13] that measurement of CSF antibodies was a more sensitive and specific method than measurement of serum antibodies by either IFA or ELISA. Even Rashmi., et al. [6] states that since IgM cannot cross blood brain barrier, CSF IgM specific to a virus is highly suggestive of brain invasion by pathogen and this provides early, quick and accurate diagnosis.

The prevalence of bacterial meningitis (7.5\%) in the present study is in consistent with studies conducted by Sasan MS., et al. in Shiraz-Iran (12.3\%) and Hosseininasab A., et al. in Mashhad-Iran (16.3\%) [14].On contrary, a higher prevalence of bacterial meningitis was reported in Indian studies conducted in Kolkata by S. Joardar., et al. (34.66\%) [15] and in Tamil Nadu by Minz S., et al. (18.56\%) [16]. The low rate of bacterial meningitis in this study can be due to immunization, prior admission in different hospitals, administration of empirical antibiotics prior to lumbar puncture. Our study is in consistent with the explanation by Bareja R., et al. [8] that regional variations in aetiology is seen even in close geographical locales and races. Among bacterial agents, S. aureus, E. coli, $K$. pneumoniae were most common which is similar to other studies $[8,17]$.

In the present study, it was observed that bacterial meningitis was more in neonates (50\%) whereas viral meningitis is observed to be more in infants (38.4\%) this is in consistent with Wang YJ., et al. study [18]. Bacterial meningitis cases showed specific features like fever, convulsions and meningeal signs which is in consistent with Sonavane AE., et al. study [19]. Viral meningitis showed fever, convulsions, altered sensorium and irritability, non-specific features and meningeal signs which is in consistent with Wang YJ., et al. [18] study. In the present study, pleocytosis was defined as $>10$ white cells $/ \mathrm{mm} 3$ for neonate and $>5$ white cells $/ \mathrm{mm} 3$ for others and findings of biochemical and cytological analysis were in consistent with other studies $[6,18,20]$. It was observed $100 \%$ raised serum CRP in bacterial meningitis which is in accordance with P L Prasad., et al. study who reported raised Serum CRP in 29 cases of bacterial and zero in all cases of viral meningitis [21]. According to Schwarz S., et al. although CSF lactate and serum procalcitonin have been reported to be useful to distinguish bacterial meningitis from aseptic meningitis [22], they were not routinely checked in our department due to high cost. Majority of Normal CT/MRI brain scans suggesting of meningitis is in consistent with Nagra I., et al. study [23]. In this study, it was observed that $83.6 \%$ recovered with early intervention and management in meningitis cases. Early identification for specific cause will decrease the disease burden and prevent unnecessary use of antibiotics in viral meningitis cases.

\section{Limitations}

To establish the aetiologies of meningitis, sensitive strategies for the diagnosis of organism need to be explored. CSF cultures were negative for bacterial aetiologies because of administration of empirical antibiotics prior to hospitalization. Although many viruses cause viral meningitis, only 3 viruses were studied in this study because these were most common causative agents, cost restrain to study all viruses, unavailability of comparable published data in our region. As cost remains a significant barrier for molecular diagnostics, So we have adopted CSF ELISA in correlation with other available tests in our settings. For detection of parasitic agents, direct wet mount of specimen which is a low sensitive test was adopted due to unavailability of resources for specific diagnosis in the present settings.

\section{Acknowledgement}

Grateful to my mentors Dr P Shashikala Reddy, Dr D SudhaMadhuri for conceptualising the topic, guidance through work, reviewing and editing the content. I extend my thanks to Dr M Alimelu , Professor, Department of Paediatrics for immense cooperation and also grateful to laboratory technical staff, patients participated. 
using multiplex real-time polymerase chain reaction". Acta Medica Mediterranea 34 (2018): 127-132.

\section{Bibliography}

1. Yerramilli A., et al. "A study on the clinical outcomes and management of meningitis at a tertiary care centre". Neurology India 65 (2017): 1006-1012.

2. HFM Farag., et al. "Epidemiological, Clinical and Prognostic Profile of Acute Bacterial Meningitis Among Children in Alexandria, Egypt". Indian Journal of Medical Microbiology (2005).

3. DR J Nageswararao., et al. "Study of Bacterial Meningitis in Tertiary Care Hospital". IOSR Journal of Dental and Medical Sciences (IOSR-JDMS) 15.1 (2016): 01-16.

4. "Global, regional, and national burden of meningitis, 19902016: a systematic analysis for the Global Burden of Disease Study". The Lancet Neurology 17.12 (2016): 1061-1082.

5. JayaramanY., et al. Hospital Based Sentinel Surveillance of Bacterial Meningitis (HBSSBM) Network Team. "Burden of bacterial meningitis in India: Preliminary data from a hospitalbased sentinel surveillance network". PloS one 13.5 (2018): e0197198.

6. Rashmi Kumar. "Aseptic Meningitis: Diagnosis and Management". Indian Journal of Pediatrics 72 (2005).

7. PV Borade (Gedam)., et al. "Study of Morbidity and Mortality Pattern of Cases of Meningitis Admitted in Tertiary Health Care Centre in India". International Journal of Recent Trends in Science and Technology 10.2 (2014): 213-217.

8. Bareja R., et al. "Trends in bacterial etiology amongst cases of meningitis". Journal of Academia and Industrial Research 1 (2013): 761-765.

9. Meningitis|Home|CDC.

10. Nathan C Bahr and David R Boulware. "Methods of rapid diagnosis for the ethology of meningitis in adults". Biomarkers in Medicine 8.9 (2014): 1085-1103.

11. A Pormohammad H., et al. "Epidemiology of herpes simplex and varicella zoster virus in cerebrospinal fluid of patients suffering from meningitis in Iran". New Microbes and New Infections 36 (2020).

12. Sirin MC and Goktas S. "Determination of the prevalence of viral, bacterial and fungal pathogens cau-sing meningitis by
13. Goran TS., et al. "Diagnosis of Spirochetal Meningitis by Enzyme-Linked Immunosorbent Assay and Indirect Immunofluorescence Assay in Serum and Cerebrospinal Fluid". Journal of Clinical Microbiology 21.5 (1985): 819-825.

14. Mohammad Saeed Sasan., et al. "Epidemiology of Aseptic Meningitis in Infants and Children (Shiraz - Iran)". Archives of Clinical Infectious Diseases 7.4 (2012): 116-118.

15. Swarnali Joardar., et al. "Meningitis in Children: A Study in Medical College and Hospital, Kolkata". Bangladesh Journal of Child Health 36.1 (2012): 20-25.

16. Minz S., et al. "Incidence of Haemophilus influenzae type b meningitis in India". Indian Journal of Medical Research 128 (2008): 57-64.

17. Fatima Khan., et al. "Bacterial Meningitis in North India: Trends Over a Period of Eight Years". Neurology Asia 16.1 (2011): 47-56.

18. Wang YJ., et al. "Comparison of Childhood Aseptic Meningitis with Bacterial Meningitis in a Tertiary Children's Hospital of Taiwan". Journal of Meningitis 1 (2015): 103.

19. Sonavane AE., et al. "Pattern and antibiotic susceptibility of bacteria isolated in clinically suspected cases of meningitis in children". Journal of Pediatric Neurosciences 3 (2008): 131133.

20. Fitzwater SP., et al. "Bacterial meningitis in children $<2$ years of age in a tertiary care hospital in South India: an assessment of clinical and laboratory features". The Journal of Pediatrics 163 (2013): S32-S37.

21. Prasad PL., et al. "Childhood Bacterial Meningitis and Usefulness of C-reactive Protein". Medical Journal Armed Forces India 61.1 (2005): 13-15.

22. Schwarz S., et al. "Serum procalcitonin levels in bacterial and abacterial meningitis". Critical Care Medicine 28.6 (2000): 1828-1832.

23. Nagra I., et al. "The role of cranial CT in the investigation of meningitis". JRSM Short Repots 2.3 (2011): 20.

Volume 4 Issue 12 December 2021 (C) All rights are reserved by Dr D SudhaMadhuri., et al. 